\title{
School libraries archive community images
}

\author{
Peng-Shun Peng \\ Director of Library \\ National HsinChu Senior Industrial Vocational School
}

Taiwan

Jiann-Cherng Shieh

Associate Professor

Graduate Institute of Library and Information Studies National Taiwan Normal University

Taiwan

As multiculturalism is becoming a world value, the creation, culture, and common memory of the community nowadays should be the running water source of "The National Digital Archives Program." However, while we are making great efforts to improve the creation of the local cultural community and multicultural development, the connotations of the community culture, as well as the local anecdotes, which are closely related to our daily lives, are definitely worth recording and passing down. Thus, as a place of knowledge collecting and culture reservation, the school library should play a more positive role in the community changes which are related to the economic development, the urban style, the basic necessities of life, the languages, and the humanity characteristics. One of the important tendencies in the present education reform in Taiwan is the cooperation between the school and the community. With the school library open to the public, the number of people that the school serves will increase and the interaction between the school and the community residents will be more frequent. If the school library has a good interaction with the local community residents, it will become a wonderful place for the community residents to have access to gaining knowledge and receiving lifelong learning. Therefore, with the application of the digital technology in the library, the digital archives of the community cultural images can not only preserve related data effectively but also disseminate and introduce the local history and characteristics to the world through the Internet. In addition, they can be served as valuable digital cultural materials for people to learn, to educate and to study. The study attempts to archive the community images by promoting the creation of digital images. Through the conformity of school teaching activities, the promotion of the use of the library, and intervention the community cultural events, we encourage teachers, students and the residents to record the history, geography, customs and humanity of the community by means of the creation of digital images, documentaries for example. As a result, we hope that the digital image of the common memory of the community would be created gradually and the library would be more multi-functional and become a place to keep the local data, to improve the understanding of the community, to offer the teaching materials and to raise the local consciousness.

Digital archives, team teaching, community images 


\section{Research Background and Motives}

The advancement of information technology has transformed the management and inheritance of knowledge, changed the dissemination and storage of information, resulted in revolutionary impact on the human society, and allowed all countries to enhance their competitiveness continuously.

National digital archives can effectively enhance the accumulation, inheritance and utilization of knowledge, and is a fundamental link to knowledge-based ecology. Taiwan is a leading country in information production and service, and its network infrastructure is maturing. It also has made significant achievement in the Chinese market and research of Chinese literature. The government has announced its mission in developing knowledgebased economy and building a green technology island. As countries worldwide are promoting digital archives (such as the Memory of the World Programme of the U.S, and American Memory of the U.S.), Taiwan also needs to expedite in the promotion of digital archives program to accelerate the upgrade of cultural information industry and ensure the advantages in academic development (http://www.ndap.org.tw/1_intro/history.php, 2004.11.16). At present, the government has made efforts to carry out a series of digital archives programs, of which, the largest one is the "National Digital Archives Program" of the National Science Council (Lai, 2001). Since effective inheritance of knowledge is the principle of archives, the significance of digital archives is to digitize the information and store online for public access (Hsu, 2001).

According to Director Ching-jun Hsieh of the National Digital Archives Program, "Digital archives, without text description, are merely garbage." This tremendously large "knowledge project" is to reconstruct the knowledge that was once hidden in the literatures or utensils for future application (Hsieh, 2003).As the society enters into the $21^{\text {st }}$ century, the advancing countries are focusing on the development of aeronautical technology, biotechnology, grand libraries, and virtual libraries and museums to manifest the national power, and its ability to move into the new century (Wu, Lin, Huang, Yeh, 1999). At present, the contents of the National Digital Archives Program mainly included animals, plants, geology, anthropology, documents, utensils, paintings and calligraphies, maps and remote sensing images, metal and stone ink rubbing, ancient books, archeology, and news. However, are the community culture and folklores that are closely associated to our daily life worth documenting? The digital archives at presents are mostly based on pictures and texts, while videos are mostly news reports. The image data on the local communities are deficient. Since the local culture and unfold the significance of heterogeneous culture, documentaries should be the focus of attention. They are familiar to the public; the people are the main characters in the documentaries, and can narrate the history and interviews. This is the difference between documentaries and other forms of creation (such as poetry, novels, drama) (Chiou, 2003), and documentaries are the most suitable form of presentation of the folk culture.

Schools can share resources with the community, and libraries should be expanded into the center for archiving community memory. School libraries can use information technology and digital media to establish the digital archives of the community. Community is built by numerous families. Besides the improvement of living quality, the cohesion of spirits and nurturing of souls can allow people to deliberate on sharing the common memories of the community. The memorable people, things, or objects of each family can inspire the whole community and reveal moving qualifies. Therefore, "family" and "family members" are the focus of this study, which aims to unfold the diverse imaginations of life through the thinking process of the subjects, and use different forms of creation to explore the life 
conversation between the family and its members. It can contribute practical documentaries for the collective development of family memories, and provide a new possibility for the production model of digital image media in libraries.

\section{The Development of Digital Archives}

Digital Archives mean the process of storing digital collections in digital forms, specifically speaking, the long-term storing, preserving and indexing of digital collections. Some of them are original digital data media while some are changed into digital objects due to digital storing. The main goal of digital archives is to ensure the availability, persistence and wisdom integration. In light of the vast increase of data, the libraries and historic archives of the advanced countries in the world, are constantly researching the methods of digital archives to enhance the period and quality of storing data.

The definition to the Digital Library according to American Digital Library Federation is "an institution which owns relevant resources such as software and hardware equipment, network and professionals. Its main purpose is to choose, organize, supply, interpret, transmit, preserve the digital collections and make them quickly and economically utilized by specific users.” (Digital Library Federation, 1999). As a result of the Internet and electronic technology, all the countries hope to digitize, preserve, and protect important cultural heritage of mankind and to provide indexing to promote the flow of the cultural data and more value-added applications. Therefore, to establish digital libraries or digital archives, has become the common ground to advanced countries. The programs we are more familiar with are the "Memory of the World" program promoted by the United Nations and "American Memory" program. The United States has promoted "American Memory" (http://memory.loc.gov) program since 1990, which made collections, manuscripts, photographs and videographic data digitalized. In Europe, the digitization of culture and history is much stressed. The research teams including the Vatican Museum, National Gallery, London British Museum, the Louvre in Paris etc. are working on the digital archives program. Vatican Museum digitalized precious Vatican manuscripts to provide scholars of the world to do the historic research; the Louvre focused on the digitalization of collections and the technology of multimedia. "Canada's Digital Collections" (http://collections.ic.gc.ca) program is mainly to transform collective data of antiquities into the digital exhibits and to provide the teaching resources of curriculum and classroom activities.

Since 1998, we have done research on digital archives for nearly 10 years. At the beginning, due to the attention to internet content and quality, we presented "National Digital Archives Program" to promote the digital preservation of precious cultural assets of our country. In 2001, on account of the trends and demands of digitalized environment, we expanded "National Digital Archives Program" to Taiwan e-Learning and Digital Archive Program”, based on "Digital Museum Project", "Digital Archive Project" and "IDLP" and reintegrated the program according to the whole development of the country to carry out the digitalization and promotion of collective resources. With the support of our government, institutions including National Palace Museum, National Museum of Natural Science, Sinica and the National Library are taking part in the Digital Archives Programs. In 2007, the year of second stage of NDAP(http://www.ndap.org.tw), in addition to digitalizing various data, we also looked forward to promoting creative and innovative value-adding application and learning. Since 2008, NDAP and TELDAP have shared digital resources with each other and developed the advantages to promote the application of national digital knowledge and boost 
the progress internationally. The goal of the plan is "the variety of Taiwan archives, and deepening of e-learning”.

To digitalize important culture, history, and academic data is one of the important methods to preserve cultural assets which the plan is aimed at preserving. However, how to properly use the results of the program to boost the human, social, industrial and economic development is also an important topic. The basic function of the library is "to preserve the information by collecting. Because of easy access to information and means to facilitate the transmission, it provides instructive and creative reading, observing and audio-visual information for the people of different ages. It is the vital part in the world culture and educational system, and an important institution of preserving cultural heritage in society. Thomas Frey listed the top ten trends of influencing the development of the library in the article "The Future of Library". One of them is "the library will be transformed into cultural centers from information centers.” (Frey. T., 2005)

In recent years, there are many positive developments in Taiwan society as a whole. Whether it is the infrastructure of information and communication, educational reform, economic liberalization, or the government enhances the quality of the manpower and promotes lifelong learning as well as information of the government open to the public. They are declaring the new era of information services. Libraries in "DELDAP" have been playing an important role. In human society, libraries play the part of delivering wisdom and transmitting knowledge. Especially, in the society of information, libraries are owned and shared by the public; they provide chosen and organized information as well as comfortable reading rooms for self-learning. It is the foundation for a progressive society. Libraries are not only the main institutions of collecting, organizing, and delivering information in a progressive society, but also for the government to declare news and for lifelong learning of people.

"Making use of information technology, digitalizing cultural records, strengthening the media centers in the elementary and high school library and diversification of teaching resources" are listed in the report of developing our library industry as one of the goals of development, showing that the library should not just be a passive collector, but should play the role of an active creator and producer.

\section{School Library and Community}

The Committee of Education Reform, which is under jurisdiction of the Executive Yuan, proposed in 1996 the "Direction of the New-century Education", in which the importance of "a lifelong learning system" is emphasized. It is essential that more attention should be paid to the relationship between families and communities so that every corner in both of them can be a good learning environment. The goal is to create community schools and campus communities. Schools and communities support each other and build up community learning system, so as to integrate the resources of schools, communities, cultures, and industries.

It is the core of successful education reform that schools, families, and communities get close to one another and make two-way communication, mutual participations, mutual sharing of resources, and supportive cooperation. A community which has common consensus, traditions, ethics, and the identification of community concept may develop into a 
highly-identified one. Combined with community resources and coherence, educational features can be displayed and promote progress and prosperity of the community foundation.

From the 20th century to the 21st century, the relations between schools and the development of community have undergone considerable changes. During this period, schools gradually break through the old frame and turn into a spiritual fortress. That they are open to the public is a concrete evidence. The functions of school are not only to educate students but also to expand the service to the community.

The school library is a learning and cultural place. By the library, one can find inspiration to settle down with a flexible source of learning at any time, not only life lessons, skills, but also knowledge of all aspects of knowledge and wisdom. Library is the best place for lifelong learning and to educate the general public has its own sacred mission and responsibilities. Adopted in 2002, the Library Law stipulates the implementation of the Education Library. Of them, "to be the Learning Resource Center" and "to meet the lifelong learning policies and serve the people in the community" echo the objectives of libraries in schools and communities to play a service-oriented role in a broader viewpoint.

Towards the twenty-first century, an era of lifelong learning, libraries' mission is no longer simply editing the book information, collection, browsing, and other reference task, and more importantly, combined with community resources to become a life-long learning center. Let the libraries of twenty-first century be a resource learning center for the public. To be a life-long learning center, library in a community should realize the self-learning requirements of the residents and available resources in the community and then integrate both of them. Libraries are necessarily and moderately to expand the educational function, actively planning to participate in educational activities, community integration of the various learning resources and making arrangements for the learning activities. In this way, libraries will become a community learning resource center for lifelong learning and play an important role in social responsibility for social education. It is the mission of library in the new era.

The documents about local cultures and customs record the specific events of a certain place. They preserve history and culture and are generally divided into three categories: books literature, artifacts, and audio-visual and electronic information. They make the preservation of local historical materials, enhance mutual understanding of different places, provide local learning materials and make local consensus. If transformed into electronic files by the way of digitalization, these valuable traditional media will be endowed with modern meaning and increase the value of the following:

1. Through the Internet, digital information can spread and introduce local culture, history and characteristics.

2. The local information and its related series can be preserved effectively.

3. The establishment of valuable database can become digital materials to benefit education, study, research

Local information is of a large amount and the cost of digitalization is very expensive. Therefore, what kind of information should be preserved as Digital Archives? We believe that this question can be considered from several aspects: 
1. Have a plan to establish a database for existing files, such as possession of a celebrity's manuscripts, diaries, letters and so on.

2. Have a plan to establish a database on a particular theme, such as the Hakka folk song database, a database of local ancient monuments, or traditional customs database.

3. Create a database for the valuable existing collections.

Local (community) culture is not only the local history and cultural heritage, but it is living educational materials. Local (community) culture is a kind of cultural memory and a kind of dream.

\section{Digital Archives is the Community for the Course}

The researchers try to approach record-chip collection of community (family) memory. Record with voice as a film of the tools and channels, the characteristics of the times reserves the right to become a record of the times. Images taken with the text will record the historical development of the community.

\section{Creative documentary " Fen Mei "}

This is the period of 2004-2005 years through interviews with family members and spiritual dialogue, to capture their observations, impressions, memories of the process of Ms. Fen Mei, a traditional Hakka woman outline sketch of the image; a view to provide multiaudience to imagine the lives of women and Hakka interpretation of imagery, but also the collective memory of the family record of community image, provide an alternative thinking, and explore among the home ,families , self-life with their dialogue.

This video is pronounced in Hakka language. Language is like windows, you can open people's views ; the more you are familiar with language, the more precious cultural assets you will own. It helps a lot to national development and national integration.

Researchers kept records with his mother tongue---- land- and- sea Hakkanese cavity as the main voice, full of the Hakka slang in their conversations. The natural flow disclosure is worth to be good examples as their mother tongue learning and demonstrations.

\section{Documentary " Fen Mei " for the course}

" Fen Mei " video contains 8 vol. The entire process of photos is completed by me alone. With the exception--- when the old lady set out to reproduce the back and forth on the road to the Church, I had to drive, so I asked my wife to assist me in filming. The first clip of the film is 52 minutes long version at the same time I begin to work on the subtitles because more than $90 \%$ of the film is pronounced in land- and- sea Hakka cavity. For me, the subtitle is actually the severe test to my mother tongue.

Images in Hsinchu City Museum was held in a small screening room to watch the early-cut film. And the instructors proposed that I control the film within 30 minutes long. Way home at that night seemed to be longer than before. Editing the work of the subtraction 
is not a simple mathematical formula, I knew there would make me sleepless several nights. The only consolation is that the instructor told me: "you are good at story-telling!"

It reminds me of the kindergarten time in the past; I was asked to stand in front of grandparents ,” Ah-hoon' tell stories for us, “, my grandpa would say. Then I began to report what happened at school a whole day. I would be rewarded a dime or two cents afterwards. That was the dime I bought "dammarane Ami"-candy for myself. The instructor praised me and I felt I returned to the good old days of childhood; I temporarily forgot that the "control the piece within 30 minutes long."

1. Video Type: documentary realism of health

2 . Video Length: 40 minutes

3. Narrative structure (the original idea): the subjective camera styles for access memories, lifting the ripple of past; objective one is to capture the true nature of the respondents vs. light and the implied criticism into the scene.

\section{Video Name: Fen Mei}

5. The main sections of video

\section{(1)Course titles}

After a home (echo the name of Taiwanese wife), Hakka ladies are full of documentary footage of life (calm , quiet, and chirpping background), a quiet old house and all the people, things will be settled in the in the Aquarius years long ... Like the reflection of the lens, fading color slipped over each old stores and the old road. This is the section of road with Grandpa, even though it is only a day of worship to a church, accompanied by her grandchildren , ringing repeatedly an atmosphere of relying on one another, with trust and warmth ...(Music fades out)

(2)The first scene Fen Mei's big daughter-in-law:

Fragments of life dishes out to disclose the true portrayal of female Hakka, illustrating slowly the mother-in-law, who studied hard to learn Manderline and sincerity to God (we should go to church in the early morning). But her behaviors always made the younger generation feel ridiculous; being a poor cook, the mother-in-law made rice cake in a mess, although the father-in-law diliked the cake, it ended up with the dishes of New Year Eve cooked by the father-in-law instead. She was easy and free! Softness can overcome strength—a female who was born pure-minded in her nature.

(3)The second scene: Fen Mei's first grandson

A sculptor who is good at keeping others by a deep face he sculptured, the day after overnight working, with sleeping eyes, he recalled the Grandma.

(4)The Third scene: Fen Mei's second daughter-in-law

The second daughter-in-law has always been capable of humility, still admires and respects Grandma when the mother-in-law even more decent than she. The younger follows 
Grandma in praise , learning style of the elderly! Such as: a dignified appearance, emphasize on images all the time)

(5)The Fourth scene: Fen Mei's second son:

The son mentioned the devout mother's worship to God, with knees knelt down to pray along the road, it impressed him deeply. It was a pity that Mother was sick and could not attend the company travel. He couldn't express gratitude to Mother any more.

(6)The fifth scene: Fen Mei's third sons:

Youngest and the most cherished son owned painful memories of his mother, giving him a cup of Sun-tea in the final exams, showing her love, still made the third shed tears now! Mother had depression and committed suicide once, and the mother lost pocket money but gave the chance to have interaction in mind with him. Expanding loss in Indonesia's business caused him to lose the last meeting with Mother, so it depressed him greatly.

(7)The Sixth scene: Fen Mei's third daughters:

The daughter was sold at a young age and learned more instinct of life from difficult life (her own way to pickle), still had gratitude for his mother who ever secretly held rice to help her and filmed in the fragment. So when she served the old mother with chicken soup cooked by herself , and won Mother's praise, she still expressed her sense of achievement.

(8)The Eighth scene: Fen Mei's Seventh daughters:

The Seventh daughter who bought vegetables from the market in the traditional imaging the daughter who was sold to a relative when she was young. She remembered clearly each kind of food, fruit which her Mother liked to eat. When she recalled of following Mother to a Catholic church, still felt proud of it. The rosary cross on his chest is the only memory which she owned Mother in mind.

(9)The seventh scene: Fen Mei's granddaughter:

The lighter affection between grand-daughter contrasted the daughter's love to Mother; it is the generation gap indeed. The problem of childhood wonder is a kind of affection while growing up, you can not give up, can only attach to it. So when she married a foreigner, could better understand Taiwan's Hakka traditional close kinship and family integration of the power of cohesion!

(10)At the end of the scene

Like the flow of the yellow street, echoed the warmth ------< Grandma! Be sure to take a seat! >

6. Closing words card, with music staff and the guidance of Professor ... ...

7. Language and monologue: the vast majority of Hakka, a very small amount of tone in Mandarin at the scene with no monologue

8. Subtitles and graphics, music and sound effects: figure of on-site full subtitles; have situational soundtrack music 
9. Sources and skills of the screen: DV1000 video / Main Hoon peng-shun peng photography. Hand-held photography, part of the tripod Self.

\section{Conclusions and Suggestions}

In the time when multiculturalism becomes the universal values in an era of globalization, the development, the culture and the collective memory of communities should be the source of the "Digital Archives Program." What is culture? It should be the concrete presentation of the life of a social group. Only when there is a close connection between the culture and land, and people's lives can the culture be meaningful and as fresh as the water at the origin of a flowing river. School libraries should be the cultural center and memory collection station of a community so that they could actively participate in community interaction and thus keep the digital imaging works of the community memories and retain parts of the collective memory of the people to become a treasure, beyond materialization and with humane thinking.

The study will focus on Fen-Mei, the "sketch," and the "value of life" is the center of my recording. While sharing, I began to think of what the family spirit in the future will be and how we could extend it? Then, I found that the value of life is the center of the recording. When facing Fen-Mei, what comes to her descendents' mind? The sharing of the children and grandchildren in front of the camera and the track of thinking and argumentation lead us to certify our future road clearly. I assess the effect of the film will help achieve the following: First, the film can offer a sample for the memory of transitional families in Taiwan in the twenty-first century; Second, the film presents a variety of lifestyles and the concepts of life and thus can be used as a reference for the domestic education on life; Third, the film's depiction of the image of the Hakka female in Taiwan provides an imaging record of how to carry out the reality; Fourth, the film offers an example for women who would like to grow and to change their ideas about the value of life. Finally, the film gives a practical model for the cultural digital memory collection in local communities.

Through the feasibility of the creation of a documentary, the school library plans and designs a number of teaching curriculum and activities with the purpose of establishing a community of digital archives gradually. The following are the curriculum and the activities:

1. Planning New Year celebrations and tours of finding the family roots: Sixty video entries or so from the six community vocational high school schools are expected to participate in the competition. On special Chinese festivals, school libraries cooperate with Chinese teachers. We hold activities, like the tour of finding the family roots, in which students are asked to videotape or use their words to record the development of the community. We also have a short film competition. The inspiration is from the famous movie "Cape No.7," originated from a bunch of love letters. Students may trace their fascinating family memory or root back from a photo, a flight ticket, a ticket to amusement parks or even a toy. Besides, with the community-based project funding, we organize "Hsinchu Impression" Digital Design Competition (the deadline of the recipient is June 1, 2009). With the competition, we hope to encourage the high school students in the community to observe the local people, and record with images and words. On the one hand, the competition allows the young generation to care about. On the other hand, students will learn to know rational thinking and the importance of recording. The activity not only help preserves the different perspectives of community information, but also stimulate the creativity of teachers and students. 
2. The design and application of co-teaching: We have completed a production of 42 e-books related to the community history and geography. The school library cooperated with geography and history teachers to design and plan a teaching unit called "Understand Your Hometown." Through teachers' teaching in class, as well as the book exhibitions of related topics on local history and geography, the students learned to use the imaging technology to introduce the streets, temples, monuments, and local snacks in their hometown. With the references offered by the library, the students were able to produce several excellent briefings, and to present the images in detail and vividly. After their presentation, the library collated the presentations and turned them into e-books, and posted them on the library website for teachers, students and people in the community. This activity not only helps set up the database of the related community imaging data but also provides history and geography teaching with abundant teaching resources.

3. The promotion of community arts activities: We have completed two documentaries about the cultural activities in the community, "Behind the winner" and "Hsinchu Chenghuang Festival Concert." Walking out of school libraries, we put our effort in supporting the community. We served as volunteers for the communities or accepted their request to help the community promote artistic activities. Besides, we recorded the reality of the art groups' practice and the performance in the community to collect the struggling process of the community activities.

The researcher accepted the request from a remote primary school in assisting filming "The Process of Elementary Schools Participating in the process of music competitions." We recorded the process of students' hard training before the competition and the authentic expression of them when facing difficulties and frustrations faithfully. When shooting the film, the researcher witnessed the interaction between teachers and students and the community and how the students broke through those difficulties and finally won the victory after tears of bitterness. That was the most innocent story of the community!

In the pioneering culture activity, "Chenghuang Festival," the library staff assisted in filming and recording the concerts of the festival in order to seize the splendid moment for the community. It was quite rare when dozens of Chenghuang gods all over the country gathered together. Coupled with the deafening din of gongs and drums of the music, the joy and a sense of accomplishment were beyond description.

With the practical creation of documentaries and the cooperation of activities and teachings, we have several suggestions for the operation of the community image archives in the school library. The following are our suggestions.

1. Teachers are encouraged to relate students' learning to the cultural activities in the community with the design of their teaching contents. This could vitalize their teaching content and implement the effectiveness of the learning.

2. he school library can offer basic photography courses for the people in the community to and encourage community groups to write and record stories for the elderly people so that the paragon could be transferred to the younger generation.

3. Because the photographic equipments have become increasingly common, documentaries could very well be acted as a basic and practical way to record digitally. Therefore, it is better to encourage the people in the community to have dynamic records. We hope that the records 
will not only collage the images of Taiwan in politics, society, culture, and economics but also reflect the vitality, freedom and different voices and issues.

4. The school library should organize community documentary film festivals at certain moments so that teachers and students will have the opportunities to learn from each other, and to expand the effectiveness of the community digital archives.

5. Teachers and students are encouraged to get out of the school for community service and make use of their ability in technology and equipment, in order to leave a valuable record for the community as well as enrich the school library collection, local reference for teaching resources, which will lead to a three-way win situation.

6. With the population and easy access to information and technology, teachers, students and people in the community are encouraged to participate in diverse digital collections so that they could build self-confidence, and work more on community culture.

The Executive Yuan in Taiwan has proposed the "Six-Star Healthy Taiwan Community Project." Its major objective is that in order to develop a healthy and diverse community and strengthen peoples' awareness of taking part in public affairs actively, we should establish a bottom-up proposing mechanism, strengthen the foundation of the mutual trust among ethnic groups, and expand peoples' participation. As a result, we could establish a social environment which will be "growing constantly, results sharing, and responsibility sharing." Since the school is part of the community, without a doubt, it should contribute its effort to the community. With the design and effort in each aspect of the school library, we can leave digital imaging recordings for the humanity image model in the community, which is also a way to show how the library actively participate in public affairs. Hopefully, with the study, we could unite the community families, strengthen the family bonds and the identification with the community. Also, we hope to inspire the youngsters in the society to join us to cultivate the awareness of self-interpretation. Finally, with the participation of the youngsters, we could help train the talents in the community and hope the process of empowerment will encourage more people to take part in the community cultural digital archive and together, create the "Taiwan memory" where we belong to.

Kim Yong Wo, a national treasure scholar in Korea, once said, "In the flow of globalization, a fundamental problem in a regional culture is the maintenance of self-identity; globalization is actually the localization, which is not a kind of "formation, rather, "peoples' identity." Self-identity is not to "look down on oneself"; and culture, is the most forceful power to fight against a strong enemy.

\section{Reference}

Ying-Jui Ching(2004),Process, tool, and will, Artistic Aspect,21.01 ,24-29.

Ya-Wei Wang Michael Rabiger(2004), Documentary, Taipei Yuan-Liu Publisher.

Wei-Tzu Wang(2003)Development of genre and analysis of Taiwanese documentaries-centering on Bill Nichols’ six models, Journal of Radio \& Television Studies(National Chengchi University),20,1-33.

Jia-Sin Ho(2003)。A Study on integrated searching performance of heterogeneous systems---With Chinese Information Portal Site as an Example,Graduate Institute of Library \& Information Studies National Taiwan Normal University Thesis.

Meng-Hou Ho(2004),Issue, phrase,National Museum of Prehistory E-paper,37.

Mei-Mei Wu、Shan-Ru Lin、Mu-Syuan Huang、 Nai-Ching Yeh(1999),Cases and plan on digital museums --- Self-assessment of digital systems,Digital System. 
Tsui-Ying Li(2005),Culture, the most powerful tool against mighty enemies-cooperation and reciprocity , Windows of Culture,75,4-5.

Kun-Cheng Lin(2003),Image of Home: Photographic Creation of Lin Kun-cheng,Graduate School of Visual Arts. Taipei Municipal Teachers’ College Thesis.

Li-Fang Lin(1994),Development of extension and service in libraries and learning center for information in communities,National Taiwan Library Journal,6(2),36-41.

Kuei-Fen Chiu(2003),Display of culture difference and conflicting space in the time of globalization, focusing on documentaries, Series : Cultural Studies \& Critical Theory. http://www.cecs.nctu.edu.tw/ record/ec7-3/interview.doc2005/01/23 (accessed January 25.2005).

Tai-Sin Hsu(2002),An Interoperability Framework for Digital Archives, Computer Science and Information Engineering Department, National Taiwan University Thesis.

Ai-Ti Hsu(2001),A Study of Interactive Functions in Taiwan Digital Libraries Evaluation and Users- Needs Analysis,Institute of Communication Studies National Chiao Tung University.

Wen-Tsun Chang(2004),The Opportunity and Development of Digital.http://www.iii.org.tw/itpilotmz/unit3/11.htm,(accessed November 10.2005).

Tien-Wan Chang(2004), Taiwan Hakka women, Taipei: Yushan Club.

Han-Pi Chang, Kun-Lu Wu (2003),Political and economic analysis of cultural citizens’ power, Speech on Hakka Cuture in 2003.

Heng-Ta Pi (2001),Meaning of home, Taipei: Nan-Tien.

Fang-Jung Chuang、 His-Chang Wang (2000), General discussion on library career, Library Annals, 2000, National Central Library, Taipei: National Central Library.

Hsing-Fen Chen(2002),house women home, Graduate Institute of Sound and Image Studies in Documentary Tainan National College of The Arts (TNCA) Thesis.

Chi-Nan Chen(1998), Handbook of Community Rebuilding for Local Administrators, Hsin-Chu City Cultural Center.

Ho-Chin Chen(2001),A Study for Metadata and Digital Archives,University Library,5(2),1-10.

Pan Chen(2003),Cultural creation experiences, focusing on experiences of Taiwan's Hakka movements, Seminar about Hakka Culture in 2003,Group Discussion: Hakka Characteristics and the Creation of Local Culture.

Te-Hsiu Peng(1996) , Hakka pronunciation dictionary, Taipei: Nan-Tien.

Wen-Chen Tseng(2002),Spring:The story of Hsu Chin-yu,The 39 ${ }^{\text {th }}$ Golden Horse Award-the Best Documentary.

Hung-Chu Huang(1995), The center of worldwide attention to digital libraries,http://www.sinica.edu.tw/ pingpu/pinpunews/readingmaterial/dg-l/dl7.htm,(accessed January 10.2005).

Brochures on digitalizing of local culture in Taiwan (2002), Handbook of local collections Digital, http:// readopac.ncl.edu.tw/ndap/loc/ndap-loc-doc-00.htm(accessed November 16.2004).

Yen-Ju Lai(2002),Digital Archives inTaiwan,CADesigner Magazine,182,121.

Presidential House(2001),Library Law,2002.01.17 Published,No 9000009320.

Lan-Chuan Yen. Yi-Tseng Chuang (2004), Mi-Le Wu, 2004 International Documentary Award- Taiwan Champion.

S. R. Ranganathan(1931). The Five Laws of Library Science. London: Edward Goldston.

Cleveland, G. (1998, March). Digital Libraries: Definition, Isuue and Chllenges. Retrieved October 20, 2003, from http://www.ifla.org/VI/5/op/udtop8.htm

Stephen M. Griffin(1998) NSF/DARPA/NASA Digital Libraries Initiative --- A Program Manager's Perspective , D-Lib Magazine July/August 1998

Digital Library Federation. (1999). A working definition of digital library. [Online]. Available: http://www. clir.org/diglib/dldefinition.htm

Frey T(2005) The Future of Libraries : Beginning the Great Transformation. Retrieved May 17, 2007,from<http://www.davinciinstitute.com/page.php/ID=120.>(2005)

American Memory,<http:// memory.loc.gov/ammem/index.html>(accessed February 10.2008)

Canadas Digital Collections, <http://collections.ic.gc.ca>(accessed February 10.200)

\section{Statement of Originality}

This statement certifies that the paper above is based upon original research undertaken by the authors and that the paper was conceived and written by the authors alone and has not been published elsewhere. All information and ideas from others is referenced. 
